\title{
Pelatihan Penggunaan Bahasa Kelas (Classroom Language) Dalam Pembelajaran Bahasa Inggris Bagi Guru SMK Jakarta Pusat 1 Jakarta
}

\author{
Martriwati $^{1}$, Raden Roro Sri Setyani ${ }^{1}$, Heni Novita Sari ${ }^{1}$, Nita Kaniadewi ${ }^{1}$ \\ ${ }^{1}$ Universitas Muhammadiyah Prof. DR. HAMKA, Jl. Tanah Merdeka, Jakarta Timur, Indonesia \\ Email:wati_uhamka@yahoo.com
}

\begin{abstract}
Abstrak
Artikel ini mengkaji terkait efektifitas Pelatihan Penggunaan Bahasa Kelas (Classroom Language) dalam Pembelajaran Bahasa Inggris bagi Guru SMK 1 Jakarta Pusat, hal ini di dasarkan atas pemanfaatan bahasa kelas oleh guru sangat penting dalam proses belajar mengajar agar peserta didik terbiasa berkomunikasi dan berinteraksi secara lisan dan tulisan. Berdasarkan hal tersebut tujuan kajian ini yaitu 1). untuk identifikasi efektivitas pelatihan Classroom Language untuk kemampuan guru-guru non bahasa Inggris dalam mengelola kelas, dan 2). untuk identifikasi efisiensi penggunaan bahasa kelas oleh guru pada kegiatan belajar dan mengajar di kelas. Metode yang digunakan yaitu menyampaikan informasi, pemberian model, dan praktik. Jumlah peserta kegiatan yaitu 41 orang guru, dengan 12 sampel kelas. Hasil analisis menunjukkan bahwa $82,9 \%$ target sasaran untuk penguasaan pengetahuan guru-guru terhadap ekspresi-ekspresi bahasa kelas (classroom language) sudah tercapai, sebanyak $87,5 \%$ peserta pelatihan memiliki kemampuan dalam melakukan pembelajaran dengan menggunakan bahasa kelas (classroom language) dalam kelompok, dan 3 orang guru (25\%) yang benar-benar konsisten menggunakan Classroom language di kelasnya dari awal hingga akhir. Sisanya guru yang menggunakan classroom language itu hanya di bagian kegiatan awal (greeting) dan kegiatan penutup.
\end{abstract}

Kata kunci: kelas Bahasa, pembelajaran, Bahasa Inggris

\begin{abstract}
This article analysis about the effectiveness of Classroom Language training in English Study for Teachers of SMK 1 Central Jakarta. It caused the using of class language by teachers is very important in the process of teaching and learning, so student get to communicate and interact for verbally and writing. Based on it, the aims of article is 1). to identify the effectiveness of Classroom Language training to improving skill manage the class for non-English teachers, and 2). to identify the efficient use of classroom language by teachers in teaching and learning activities. The method used is sharing information, modeling, and practice. The number of participants wEre 41 teachers, with 12 class samples. The result shows that $82.9 \%$ of teachers have knowledge of classroom language expressions, $87.5 \%$ of the participans have the ability to learn by using classroom language in the group, and there are 3 teachers or $25 \%$ who really consistent used Classroom language in the class from start to finish. The rest used the classroom language was only in the greeting and closing activities.
\end{abstract}

Keywords: Classroom Language, learning, English Study

Format Sitasi: Martriwati, Setyani, R.R.S., Sari, H.N., Kaniadewi, N. (2018). Pelatihan penggunaan bahasa kelas (classroom language) dalam pembelajaran bahasa inggris bagi guru SMK Jakarta Pusat 1 Jakarta. Jurnal SOLMA, 7(1), 01-07.

Diterima: 21 Januari 2018 | Revisi: 13 Februari 2018 | Dipublikasikan: 07 April 2018 


\section{PENDAHULUAN}

MASA Pembelajaran bahasa Inggris sedang berkembang di berbagai belahan dunia, dan bagi masyarakat saat ini kemampuan berbahasa Inggris aktif akan membawa dampak positif dalam kehidupan (life skills), karena banyak lowongan pekerjaan yang menyaratkan kemampuan berbahasa Inggris. Di samping itu, pergaulan yang semakin mendunia seiring dengan semakin terbukanya teknologi informasi dan komunikasi membuat kemampuan berbahasa Inggris sudah seperti kewajiban.

Bahkan bahasa Inggris menjadi bagian dari Classroom Language yang diimplementasikan untuk guru-guru non bahasa Inggris di sekolah. Hal ini sebagai salah satu bentuk kontribusi dan pengayaan profesionalisme guru dalam menghadapi perkembangan pendidikan, era globalisasi, dan khususnya MEA (Masyarakat Ekonomi ASEAN) 2016. Salah satu sekolah yang akan menjalankan program Classroom Language ini adalah SMK Jakarta Pusat 1.

Melihat perkembangan pasar saat ini dimana banyak lapangan pekerjaan yang membutuhkan tenaga kerja yang mumpuni dalam bahasa asing maka pihak yayasan memberanikan diri untuk mengembangkan proses pembelajaran menjadi sekolah atau kelas yang dwi bahasa (Bilingual Class). Dengan model pembelajaran yang dwi bahasa ini diharapkan semua siswa dan guru-guru di SMK Jakarta Pusat 1 mempunyai nilai tambah dalam akademik yaitu menguasai bahasa Inggris sebagai bahasa Internasional.

Sebagai upaya untuk mencapai tujuan tersebut, guru-guru SMK Jakarta Pusat 1 diberikan pelatihan bahasa Inggris secara bertahap. Diharapkan melalui kegiatan program ini dapat meningkatkan kualitas mutu SDM, sekolah, dan pada akhirnya untuk siswa agar dapat turut serta meningkatkan kemampuan berbahasa asing secara global. Dalam tahap awal pelatihan bahasa Inggris yang diberikan adalah pelatihan penggunaan Bahasa Kelas (Classroom Language) bagi semua guru kelas di semua bidang kecuali guru mata pelajaran Bahasa Indonesia dan Bahasa Inggris itu sendiri.

Bahasa kelas (classroom language) secara umum dapat dikatakan sebagai ekspresiekspresi bahasa yang digunakan dalam berkomunikasi di kelas antara guru dan peserta didik. Pemanfaatan bahasa kelas oleh guru sangat penting dalam proses belajar mengajar agar peserta didik terbiasa berkomunikasi dan berinteraksi secara lisan dan tulisan. 


\section{MASALAH}

Berdasarkan uraian analisis situasi dan temuan di lapangan maka rumusan masalah yang dapat dikemukan adalah sebagai berikut:

1. Bagaimanakah efektivitas pelatihan Classroom Language untuk kemampuan guru-guru non bahasa Inggris dalam mengelola kelas?

2. Bagaimanakah efisiensi penggunaan bahasa kelas oleh guru pada kegiatan belajar dan mengajar di kelas?

\section{METODE PELAKSANAAN}

1. Pemecahan Masalah

Untuk memberikan kontribusi terhadap upaya pemecahan masalah yang sedang dihadapi guru-guru SMK Jakarta Pusat 1, Tim Pengabdian masyarakat Program Studi Pendidikan Bahasa Inggris FKIP UHAMKA memberikan program pembinaan terhadap guru-guru non Bahasa Inggris di SMK Jakarta Pusat 1 dalam bentuk "Pelatihan Penggunaan Bahasa Kelas (Classroom Language) dalam pembelajaran bahasa Inggris bagi guru SMK Jakarta Pusat 1". Pemecahan masalah yang dilaksanakan adalah dengan menyampaikan informasi, berupa landasan teoretis tentang hakikat bahasa kelas (classroom language) dan peranannya, pemberian model berupa contoh-contoh bahasa kelas (classroom language), praktek membuat persiapan mengajar dengan menggunakan ekspresi-ekspresi bahasa kelas (classroom language) secara berkelompok pada fase awal, inti, dan penutup pembelajaran, dan praktek menyelenggarakan pembelajaran dengan menggunakan ekspresi-ekspresi bahasa kelas (classroom language) yang telah didesain.

2. Metode Kegiatan

Langkah-langkah kegiatan yang ditempuh adalah sebagai berikut:

a) Penyampaian informasi, berupa landasan teoretis tentang hakikat bahasa kelas (classroom language) dan peranannya.

b) Pemberian model berupa contoh-contoh bahasa kelas (classroom language).

c) Praktek membuat persiapan mengajar dengan menggunakan ekspresi-ekspresi bahasa kelas (classroom language) secara berkelompok pada fase awal, inti, dan penutup pembelajaran.

d) Praktek menyelenggarakan pembelajaran dengan menggunakan ekspresi-ekspresi bahasa kelas (classroom language) yang telah didesain. 


\section{PEMBAHASAN}

1. Tempat dan Waktu Pelaksanaan Kegiatan

Kegiatan Pelatihan Penggunaan Bahasa Kelas (Classroom Language) bagi guru SMK Jakarta Pusat 1 ini dilaksanakan di Jalan Abdul Muis No. 44 Jakarta Pusat. Waktu pelaksanaan kegiatan pelatihan dan pendampingan ini adalah pada tanggal 26 hingga 29 Desember 2016. Peserta pelatihan sebanyak 34 guru non Bahasa Inggris SMK Jakarta Pusat 1 yang dilaksanakan di Jalan Abdul Muis No. 44 Jakarta Pusat.

\section{Hasil Kegiatan}

Sebelum pelatihan dilaksanakan panitia pelaksana memandang perlu terlebih dahulu mengetahui kondisi kemampuan awal peserta pada ketiga aspek tersebut. Untuk itu dilakukan pretes, dimana data yang dihasilkan menunjukkan nilai rata-rata peserta dalam menentukan Classroom Language yang tepat adalah 50 dengan nilai maksimum yang diperoleh sebesar 70, sedangkan nilai minimumnya sebesar 30 .

Berdasarkan data di atas tampak bahwa para peserta belum memiliki pengetahuan yang cukup baik dalam menentukan dan menuliskan ungkapan bahasa kelas yang tepat dengan baik. Dari keseluruhan komponen yang ditanyakan, peserta masih belum tahu ungkapan bahasa kelas yang sesuai ketika proses pembelajaran sedang berlangsung, dan sebagian besar dapat menentukan atau menuliskan classroom language untuk membuka dan menutup kelas khususnya ketika guru haru melakukan salam (greeting) dan meninggalkan kelas (saying goodbye). Data hasil pretes menegaskan pentingnya kegiatan pelatihan Classroom Language untuk guru-guru SMK Jakarta Pusat 1 dilakukan. Setelah pelaksanaan pelatihan, tes kembali dilakukan (posttest) untuk melihat perkembangan keterampilan Classroom Language guru sekaligus menilai efektivitas dari program pelatihan. Hasilnya menunjukkan data keterampilan Classroom Language guru, setelah mengikuti pelatihan ini terjadi kenaikan signifikan terhadap nilai rata-rata yang diperoleh 72 dengan nilai paling rendah guru adalah 53 sedangkan paling tinggi adalah 90. Setelah posttest tulis dilakukan, hasil nilai praktek pembelajaran dengan menggunakan Classroom language juga menunjukkan hasil yang memuaskan, hal ini tampak dari meningkatnya percaya diri guru ketika berbicara dalam bahasa Inggris, interaksi yang terjadi antara guru dan siswa juga mulai bagus tidak lagi 
terdengar murid mentertawakan gurunya ketika berbicara bahasa Inggris meskipun masih terbatas pada penggunaan bahasa kelas saya yang tingkat dasar.

3. Keberhasilan dan keberlanjutan

Data hasil pelatihan menunjukkan bahwa telah terjadi peningkatan keterampilan guru dalam menggunakan bahasa kelas (Classroom Language). Berikut adalah gambarannya.

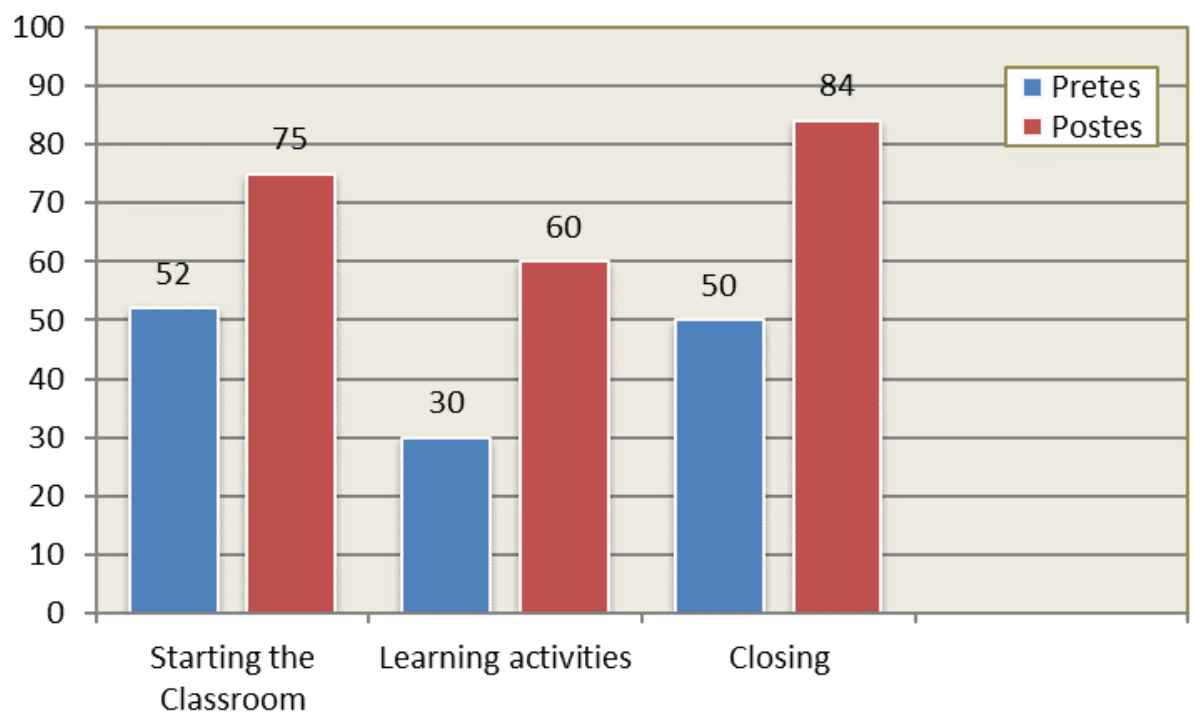

Gambar 1. Perbandingan Ketrampilan Guru SMK Jakarta Pusat 1 peserta pelatihan Classroom Language (Bahasa Kelas)

Secara rata-rata kemampuan guru SMKA Jakarta Pusat 1 peserta pelatihan Classroom Language (Bahasa Kelas) sesudah pelatihan menunjukkan hasil yang menggembirakan. Hal ini tampak dari hasil posttest tulisannya. Namun secara praktek, hasil yang diperoleh menunjukkan keterampilan guru menggunakan classroom language masih memperlihatkan kekakuan dari guru dalam mengucapkan semua ekspresi yang dibutuhkan. Ketika opening atau membuka kelas guru masih terpaku hanya menggunakan ucapan salam yang baku (Good morning,How are you saja) padahal dalam kegiatan pelatihan sudah diaplikasikan berbagai model ekspresi greeting. Ketika guru sudah sampai dalam kegiatan inti, ungkapan bahasa kelas yang dihasilkan juga masih sangat terbatas digunakan dan terlihat ragu karena takut salah dan lupa dengan apa yang sudah dipelajari. Untuk itu perlu perhatian yang lebih intensif terhadap ketarampilan dan kemampuan guru-guru dalam penggunaan Classroom Language di 
bagian Learning activities (Kegiatan Inti). Pada tahap ini guru terlihat masih bingung apa yang harus diucapkan ketika suasana pembelajaran yang terjadi bisa berubah-ubah seperti pada saat guru sedang menerangkan materi dalam bahasa Indonesia tiba-tiba ada siswa yang sibuk sendiri atau tidak memperhatikan pembelajaran.Temuan ini akan menjadi perhatian penyelenggara pelatihan kedua belah pihak sehingga kesulitan guru dapat diminimalisir. Dan keberhasilan yang telah dicapai secara keseluruhan juga patut disyukuri dengan meningkatnya komitmen untuk terus melanjutkan program secara kontinyu, baik dengan program yang sama dengan sasaran yang sama pula, maupun dengan program pelatihan yang lain yang tidak jauh berbeda dengan pelatihan sebelumnya.

4. Target Luaran

Target luaran yang akan dicapai melalui kegiatan Pelatihan Penggunaan Bahasa Kelas (Classroom Language) bagi guru SMK Jakarta Pusat 1 antara lain:

a. Pengetahuan dan keterampilan guru-guru dalam menggunakan bahasa kelas (classroom language) dengan produk ekspresi-ekspresi bahasa kelas (classroom language) yang mencapai maksimum $70 \%$.

b) Delapan puluh persen peserta pelatihan memiliki kemampuan dalam melakukan pembelajaran dengan menggunakan bahasa kelas (classroom language) dalam kelompok.

c) Tujuh puluh lima persen peserta pelatihan memiliki kemampuan melaksanakan pembelajaran dengan menggunakan bahasa kelas (classroom language) yang telah didisain.

d) Modul bahasa kelas (classroom language) bagi guru bahasa Inggris.

\section{KESIMPULAN}

Secara keseluruhan dapat ditarik kesimpulan sebagai berikut:

1. Dari keseluruhan peserta yang telah mengikuti pelatihan ini (41 orang), target sasaran untuk penguasaan pengetahuan guru-guru terhadap ekspresi-ekspresi bahasa kelas (classroom language) sudah tercapai, yaitu $82,9 \%$

2. Sebanyak $87,5 \%$ peserta pelatihan memiliki kemampuan dalam melakukan pembelajaran dengan menggunakan bahasa kelas (classroom language) dalam kelompok. 
3. Setelah dilakukan monitoring terhadap penggunaan classroom language di kelas yang nyata setelah kegiatan pelatihan diberikan ternyata dari 12 kelas sample yang telah dimonitor ditemukan data hanya 3 orang guru $(25 \%)$ guru yang benar-benar konsisten menggunakan Classroom language di kelasnya dari awal hingga akhir. Sisanya menggunakan classroom language itu hanya di bagian kegiatan awal (greeting) dan kegiatan penutup saja yang muncul.

4. Kegiatan pelatihan Bahasa Kelas (Classroom Language) mendapatkan respon yang positif dari pihak sekolah. Baik manajemen sekolah, para guru, dan para siswa.

5. Berdasarkan hasil test yang diberikan, dapat disimpulkan bahwa kegiatan pelatihan Bahasa Kelas (Classroom Language) inisecara umum memberikan dampak yang positif terhadap peningkatan keterampilan berbahasa Inggris guru di SMK Jakarta Pusat 1 khususnya dalam penggunaan Classroom Language itu sendiri.

\section{UCAPAN TERIMA KASIH}

Terimakasih kepada LPPM (Lembaga Penelitian Pengabdian Masyarakat) sebagai pemberi dana kegiatan Pelatihan Penggunaan Bahasa Kelas (Classroom Language) Dalam Pembelajaran Bahasa Inggris Bagi Guru Smk Jakarta Pusat 1.

Terimakasih kepada Smk Jakarta Pusat 1 sebagai mitra pelaksanaan kegiatan dan membantu dalam pelaksaan kegiatan Pelatihan Penggunaan Bahasa Kelas (Classroom Language) Dalam Pembelajaran Bahasa Inggris Bagi Guru Smk Jakarta Pusat 1.

\section{DAFTAR PUSTAKA}

Chang, Yu-Ying. (2010). “English-Medium Instruction for Subject Courses in Tertiary

Nation, Paul. (2003). "The Role of the First Language in Foreign Language Learning."

Paul, David. (2003). Teaching English to Children in Asia. Hong Kong: Pearson EducationAsia Ltd.

Scott, Wendy A. and Lisbeth H. Ytreberg. (2000). Teaching English to Children, New York:Longman Group UK Ltd.

(C) 2018 Oleh authors. Lisensi Jurnal Solma, LPPM-UHAMKA, Jakarta. Artikel ini bersifat open access yang didistribusikan di bawah syarat dan ketentuan Creative Commons Attribution (CC BY) license (http://creativecommons.org/licenses/by/4.0/). 